\title{
Advanced heart failure with reduced ejection fraction
}

\author{
Albert Hicks III, MD, MPH ${ }^{\mathrm{a}}$, Jorge F. Velazco, MD ${ }^{\mathrm{b}}$, Salman Gohar, MDª ${ }^{\mathrm{a}}$ Ahmed Seliem, MD ${ }^{\mathrm{c}}$, \\ Shelley A. Hall, $M^{C}{ }^{D}$, and Jeffrey B. Michel, MD
}

${ }^{a}$ Division of Cardiology, Baylor Scott and White Medical Center - Temple, Temple, Texas; 'Division of Pulmonary and Critical Care Medicine, Baylor Scott and White Medical Center - Temple, Temple, Texas; 'Baylor Scott \& White Advanced Heart Failure Clinic, Baylor University Medical Center, Dallas, Texas

\begin{abstract}
Patients suffering advanced heart failure with reduced ejection fraction (HFrEF) account for a large portion of patients admitted to hospitals worldwide. Mortality and 30-day readmission rates for HFrEF are now a focus of value-based payment models, making management of this disease a priority for hospitals, physicians, and payers alike. Angiotensin-converting enzyme inhibitors have been the cornerstone of therapy for decades. However, with treatment, the prognosis for patients with advanced HFrEF remains poor. Fortunately, advances in medical therapy and mechanical support offer some patients improvement in both survival and quality of life. We review advances in short- and long-term mechanical support and explore changes to organ allocation for cardiac transplantation. In addition, we provide a guide to facilitate appropriate referral to an advanced heart failure team.
\end{abstract}

KEYWORDS Advanced heart failure; angiotensin receptor blocker; cardiac transplantation; extracorporeal membrane oxygenation; heart failure with reduced ejection fraction; left ventricular assist devices; neprilysin inhibition

\section{CME Target audience: All physicians Learning objectives: After reading the article,} the learner should be able to

1. Recognize the poor prognosis of patients with advanced heart failure

2. Distinguish between the different types of mechanical support used to treat patients

3. Select patients who would benefit from referral to advanced heart failure cardiologists

Faculty credentials/disclosure: Dr. Hicks is interim medical director of advanced heart failure, mechanical circulatory support, and cardiac transplant at Baylor Scott \& White in Temple, Texas, and the assistant program director for the cardiology fellowship. Dr. Velazco is director of the cardiothoracic intensive care unit at Baylor Scott \& White Medical Center - Temple. Dr. Gohar is medical director of the advanced heart failure and mechanical circulatory support service, Baylor All Saints Medical Center, Fort Worth, Texas. Dr. Seliem is a board-certified interventional cardiologist completing a heart failure fellowship at Baylor University Medical Center at Dallas. Dr. Hall is chief of transplant cardiology, mechanical circulatory support, and advanced heart failure at Baylor University Medical Center at Dallas. Dr. Michel is chief of the division of cardiology at Baylor Scott \& White Memorial Hospital, Temple, Texas. Dr. Hall disclosed relationships with Novartis (honorarium/speaker) and CareDx, Abbott, and Abiomed (honorarium/consultant), and Dr. Seliem disclosed a relationship with Abbott (honorarium/ speaker). The planner and other authors have no conflicts of interest to disclose.

Accreditation: The A. Webb Roberts Center for Continuing Medical Education of Baylor Scott \& White Health is accredited by the Accreditation Council for Continuing Medical Education to provide continuing medical education for physicians.

Designation: The A. Webb Roberts Center for Continuing Medical Education of Baylor Scott \& White Health designates this journal CME activity for a maximum of 1.0 AMA PRA Category 1 Credit $^{\mathrm{TM}}$. Physicians should claim only the credit commensurate with the extent of their participation in the activity.

ABIM MOC: Successful completion of this CME activity, which includes participation in the evaluation

Corresponding author: Jeffrey B. Michel, MD, Division of Cardiology, Baylor Scott and White Medical Center - Temple, 2401 South 31st Street, Temple, TX 76502 (e-mail: Jeffrey.Michel@BSWHealth.org)

Received November 18, 2019; Revised February 10, 2020; Accepted February 20, 2020. 
component, enables the participant to earn up to 1.0 Medical Knowledge points in the American Board of Medicine's (ABIM) Maintenance of Certification (MOC) program. The CME activity provider will submit participant completion information to ACCME for the purpose of granting ABIM MOC credit.

Process: To complete this CME activity, read the entire article and then go to https://ce.bswhealth.com/Proceedings2020. You will register for the course, pay any relevant fee, take the quiz, complete the evaluation, and claim your CME credit. For more information about CME credit, email ce@bswhealth.org.

Expiration date: July 1, 2022.

$\mathrm{n}$ the United States, between 250,000 and 300,000 patients under the age of 75 have advanced heart failure, i.e., objective evidence of cardiac dysfunction, usually based on imaging, in conjunction with dyspnea and fatigue that limit physical activity. ${ }^{1}$ Heart failure is progressive and the prognosis for advanced heart failure remains poor, with an annual mortality rate averaging $25 \%$ to $50 \%$, on par with that of patients with pancreatic cancer. ${ }^{2}$ Patients tend to be evenly divided between those with preserved ejection fraction and those with reduced ejection fraction (HFrEF). While few therapies exist for heart failure with preserved ejection fraction, cardiac transplantation remains the most effective treatment option for patients with HFrEF, with 1-year survival rates of $90 \%$. $^{3}$ Yet the supply of organs is limited. Left ventricular assist device (LVAD) therapy provides an important alternative to transplantation, offering 1-year survival rates of $80 \%$ and 2 -year survival rates of $70 \%{ }^{4}$ However, misconceptions persist about which patients should and should not be referred for advanced therapies. Chief among these is a belief that HFrEF patients must be end-stage, New York Heart Association (NYHA) class IV, or near death to be considered for cardiac transplantation or advanced mechanical support. ${ }^{5}$ We review areas of progress in heart failure management and provide guidance on referral of HFrEF patients to the advanced heart failure team. ${ }^{6}$

\section{MEDICAL THERAPY}

It has been recognized for several decades that the reninangiotensin-aldosterone system plays an important role in maladaptive responses that contribute to the morbidity and mortality of HFrEF. Along with sympathetic nervous system activation, renin-angiotensin-aldosterone system activation in HFrEF leads to increases in preload, worsening afterload, and left ventricular remodeling. Angiotensin-converting enzyme inhibitors (ACEIs), beta-blockers, and aldosterone antagonists are long-standing and well-recognized mainstays in goal-directed medical therapy. Enalapril in particular has been extensively studied and shown to improve survival in HFrEF patients in a number of prospective randomized clinical trials, including CONSENSUS, SOLVD, and V-HeFT II. ${ }^{7-9}$ The neprilysin inhibitor sacubitril, in combination with the angiotensin-receptor antagonist valsartan, has been shown to have greater efficacy than enalapril. ${ }^{10}$

Endogenous peptides such as brain natriuretic peptide (BNP) have vasodilatory and preload-reducing properties and are released in response to elevated left ventricular pressures, making them attractive targets for heart failure therapy. Neprilysin is a naturally occurring enzyme that degrades BNP. In 2002 omapatrilat, a combination of an ACEI and a neprilysin inhibitor, was compared to enalapril in the OVERTURE trial for treatment of heart failure. ${ }^{11}$ The primary endpoint was a composite of death and heart failure hospitalization. Omapatrilat was found to be noninferior to enalapril but demonstrated worse outcomes in black patients and higher rates of angioedema compared to the enalapril group. In 2005 nesiritide, a recombinant form of human $\mathrm{BNP}$, in a meta-analysis demonstrated an increased risk of mortality in acutely decompensated heart failure patients compared to the control group. ${ }^{12}$ Despite the negative results of these endogenous peptide trials, further attempts to utilize this treatment pathway continued. To reduce the risk of angioedema, a neprilysin inhibitor in combination with an angiotensin receptor blocker (ARB) was studied.

The Angiotensin-Neprilysin Inhibition vs Enalapril in Heart Failure (PARADIGM-HF) trial was the largest prospectively randomized heart failure trial to date. ${ }^{10}$ It compared treatment with sacubitril-valsartan to enalapril in patients with HFrEF and NYHA II-IV heart failure symptoms. Patients with symptomatic hypotension, systolic blood pressure $<100 \mathrm{~mm} \mathrm{Hg}$, hyperkalemia, estimated glomerular filtration rate $<30$, and previous intolerance to ACEI or ARB were excluded from the trial. The primary endpoint was a composite of cardiovascular death and heart failure hospitalization. All study patients had a run-in period on enalapril, needing to tolerate a dose of $10 \mathrm{mg}$ twice a day for 2 weeks. If patients tolerated therapy, they were randomized $1: 1$ to continue enalapril or be switched to valsartan-sacubitril.

In PARADIGM-HF, the primary endpoint of cardiovascular death or heart failure hospitalization was seen in $21.8 \%$ of patients treated with valsartan-sacubitril and in $26.5 \%$ of patients receiving enalapril, with a hazard ratio of 0.80 (confidence interval $[\mathrm{CI}]$ 0.73-0.87; $P<0.001$ ). Remarkably, both rates of cardiovascular death-13.3\% vs $16.5 \%$, hazard ratio of 0.80 (CI $0.71-0.89 ; P<0.001)$ and heart failure hospitalization-12.8\% vs $15.6 \%$, hazard ratio 0.79 (CI $0.71-0.89 ; P<0.001)$-were lower in the valsartan-sacubitril group compared to the enalapril group. ${ }^{13}$ The valsartan-sacubitril group had statistically significant higher rates of symptomatic hypotension, while the enalapril group had statistically significant higher rates of cough. Based on the results of the PARADIGMHF trial, in 2016 the American College of Cardiology/American Heart Association (ACC/AHA) heart failure guidelines were updated to include sacubitril/valsartan for treatment of ACC/ AHA stage C HFrEF. The 2016 ACC/AHA/Heart Failure Society of America (HFSA) guidelines recommend starting either 
sacubitril/valsartan or an ACEI or an ARB as first-line therapy for ACC/AHA stage C NYHA class II-III HFrEF patients for treatment of angiotensin system inhibition. ${ }^{13}$ The guidelines also recommend replacing an ARB or an ACEI with valsartan-sacubitril to further reduce morbidity and mortality in stage C NYHA class II-III HFrEF patients. Despite having less angioedema than previously studied ACEI/neprilysin, sacubitril/valsartan should not be administered to patients with any history of angioedema. The therapeutic success of valsartan-sacubitril highlights the important role endogenous peptides play in the pathophysiology of heart failure. Research targeting other endogenous vasodilators is ongoing.

\section{EXTRACORPOREAL MEMBRANE OXYGENATION}

Extracorporeal membrane oxygenation (ECMO) is a portable modification of cardiopulmonary bypass capable of supporting critically ill patients with refractory cardiopulmonary failure for hours to weeks. ${ }^{14}$ Veno-arterial ECMO (VA ECMO) withdraws venous blood via an active pump and returns oxygenated blood into a major central artery. It provides support for cardiac output and has become an important therapy for cardiogenic shock, functioning as a parallel circuit to the patient's heart and lungs. ${ }^{15-17}$

Accepted indications include shock associated with acute myocardial infarction, myocarditis, intoxication with cardiotoxic drugs, acutely decompensated cardiomyopathies, post cardiotomy, postpartum cardiomyopathy, recurrent lifethreatening arrhythmias, and posttransplantation shock when refractory to conventional management. ${ }^{14,18,19}$ VA ECMO has developed a prominent role in management of rapidly progressing heart failure noted as class 1 or 2 of the Interagency Registry for Mechanically Assisted Circulatory Support (INTERMACS) or even in patients with cardiac arrest requiring cardiopulmonary resuscitation. ${ }^{20}$ VA ECMO can be initiated in appropriate candidates if there is evidence of ongoing tissue hypoperfusion and worsening end-organ dysfunction in the presence of escalating inotropic and vasopressor support. ${ }^{18}$ Early initiation is important to maximize the potential of cardiac recovery and prevent multiorgan failure. ${ }^{15}$ Patients with severe biventricular cardiac failure can be managed with VA ECMO as an alternative to using both right and left ventricular assist devices; each option has its attendant risks. ${ }^{14}$

Patients must have a path forward prior to instituting support since this therapy is no more than a bridge to cardiac recovery, heart transplantation, or long-term mechanical circulatory support. ${ }^{15,21,22}$ Compared to other active mechanical circulatory support devices, VA ECMO can be less expensive, allows rapid improvement, and is the only shortterm device suitable for severe biventricular failure. ${ }^{17,23}$

A major disadvantage of this therapy is the lack of ventricular unloading due to creation of elevated afterload, increasing oxygen demand, and wall tension of the myocardium; in addition, blood stasis in the left ventricle will lead to pulmonary edema. ${ }^{21,23}$ Moreover, there are multiple strategies that could provide left ventricular unloading, like central percutaneous cannulation of the left atrium or ventricle or insertion of an Impella pump (Abiomed, Danvers, MA) inside the left ventricle. ${ }^{21,24}$ Pappalardo et al reported in a retrospective multicenter study in 2016 a statistically significant lower hospital mortality for the VA ECMO plus Impella group compared with the VA ECMO-only group ( $47 \%$ vs $80 \%, P<0.001$ ); the group received combined support after showing echocardiographic, radiological, and clinical signs of impaired left ventricular unloading or stasis. ${ }^{21}$ Barge-Caballero et al's retrospective series in Spain failed to show any significant clinical benefit of simultaneous intra-aortic balloon pump and VA ECMO for patients in the pre- or post-heart transplant period. ${ }^{25}$

VA ECMO has become a frequently used method of temporary mechanical circulatory support before heart transplantation and could also be used after surgery in the presence of primary graft dysfunction. ${ }^{20,26,27}$ Implementation of the new United Network for Organ Sharing donor allocation system in the fall of 2018 might result in further growth in use of ECMO in the United States. ${ }^{16}$ Overall, patients bridged with VA ECMO to heart transplantation had a higher early posttransplant mortality than patients bridged with durable LVADs as well as nonbridged recipients. ${ }^{28}$

According to the Extracorporeal Life Support Organization registry, overall in-hospital survival of patients treated with VA ECMO approximates $40 \% .{ }^{15}$ Acute myocarditis seems to have the most favorable outcomes, with survival to discharge of $55 \%$ to $78 \%,{ }^{16,18,20}$ with the worst outcomes in patients with congenital heart disease, with survival to discharge of $37 \%{ }^{16}$ Regarding VA ECMO therapy for patients with acute cardiac failure, no data from randomized controlled trials are available, as noted in a 2019 Cochrane review on ECMO for critically ill adults. ${ }^{29}$

Predictors of mortality on VA ECMO include older age, female sex, longer support time, decreased cardiac function at baseline, high lactate concentration, peripheral vascular disease, chronic obstructive lung disease, renal dysfunction, stroke, infection, hypoglycemia, alkalosis, device insertion during cardiopulmonary resuscitation, and decreased urine output ${ }^{16}$; therefore, several risk scores have been proposed for assessing the likelihood of survival to hospital discharge, such as the Survival After Veno-arterial ECMO (SAVE) score. This risk score has modest discrimination at best. ${ }^{30-32}$

The management of patients on ECMO remains complex and resource intensive. As a result, use remains restricted to specialized centers. ${ }^{16}$ Currently, not a single blood pump is approved by the US Food and Drug Administration to provide $>6 \mathrm{~h}$ of circulatory support as ECMO therapy for patients with cardiogenic shock from left ventricular or combined right and left ventricular failure. ${ }^{33}$ Despite the latest improvements in mechanical circulatory support devices, therapy of acute refractory heart failure remains challenging, with high mortality rates. ${ }^{23}$ In light of the high in-hospital mortality, costs, and ethical issues, appropriate patient 
selection for VA ECMO is of paramount importance and requires a multidisciplinary approach and a clear understanding of this therapy and its limitations. ${ }^{31,34}$

\section{LEFT VENTRICULAR ASSIST DEVICES}

In 1961, Domingo Liotta, a gifted Argentinean surgeon, was recruited by Michael E. DeBakey to develop the first artificial heart at the Baylor College of Medicine. ${ }^{35,36}$ The first LVAD emerged from this research ${ }^{37}$ as the National Heart, Lung, and Blood Institute moved to establish the artificial heart program in 1964. Initial efforts in LVAD development were directed toward mimicking pulsatile flow. ${ }^{38}$ The Novacor LVAD (World Heart Corp., Oakland, CA) and the pneumatic Heartmate LVAD (Thoratec, Pleasanton, CA) were some of the first pulsatile devices used for short-term support (bridge to heart transplantation) in 1984 and 1992, respectively. ${ }^{39,40}$ The "second-generation" devices (Jarvik2000, Jarvik Heart, Inc., New York, NY, and HeartMate II, Abbott, Abbott Park, IL) abandoned the pulsatile blood flow paradigm to improve durability. ${ }^{41-43}$ As devices evolved, the INTERMACS registry was established for patients who received durable mechanical circulatory support device therapy in the US in order to study scientific progress, trends, individual program development, and quality assurance. ${ }^{44}$ Intrapericardial devices followed (HeartWare, Medtronic, Fridley, MN), aimed at providing a significant reduction in pump size through smaller centrifugal blood flow pathways. This device also struggled with its own challenges that involved exquisite afterload sensitivity and a higher pump thrombosis rate. ${ }^{45-48}$ The 6-month follow-up data from the Momentum 3 trial were released in $2017 .{ }^{45}$ The data suggested that HeartMate 3 (Abbott, Abbott Park, IL), a centrifugal LVAD, reduced pump thrombosis and strokes. These findings were confirmed in 2019 after data on the full 2-year 1028-patient cohort was released. The device had superior coaxial flow pumps and provided a remarkable improvement in event-free survival, with only a $1 \%$ pump thrombosis rate and a $10 \%$ stroke rate. (The stroke rate dropped after 6 months of implantation. ${ }^{46}$ )

Newer developments in mechanical circulatory support aim to reduce device-related complications and improve survival and quality of life. Innovative surgical techniques involving a lateral thoracotomy and "mini" sternotomy for implantation are already being utilized. Smaller, more ergonomic lithium-ion batteries, Bluetooth connectivity, and new communication systems with easy access to critical data are expected to be available by 2021. Smarter pumps that use software to communicate across device platforms and adjust flows based on patient activity and volume are in the pipeline. Previous attempts to eliminate the driveline using transcutaneous energy transfer systems have been explored in pulsatile LVADs ${ }^{47}$ and the total artificial heart. ${ }^{48}$ In April 2019, two cases of a fully internalized LVAD were reported utilizing a Coplanar Energy Transfer System (Leviticus Cardio, Ltd., Petach Tikva, Israel) to eliminate the driveline while providing successful energy transmission and up to 8.5 $\mathrm{h}$ of unholstered support. ${ }^{49}$ Although promising, such a system is several years away from commercial availability. Today, advanced heart failure patients who are ineligible for cardiac transplantation have alternatives, with durable LVADs providing a notable safety profile, lower health care costs, reduced need for rehospitalizations after discharge, and a survival rate comparable to that of cardiac transplantation at 2 years. ${ }^{46,50}$ Although a durable total artificial heart has yet to emerge, LVAD technology continues to move forward with poise and optimism.

\section{TRANSPLANTATION}

On October 18, 2018, the United Network for Organ Sharing put into effect new national listing criteria for candidates awaiting heart transplantation. ${ }^{51}$ This change minimized geographic considerations in order to attempt a more equitable distribution of organs. The new allocation system prioritizes the sickest individuals (e.g., those with temporary left ventricular support including VA ECMO) and lowers the priority of individuals on home inotropes or LVADs. This is the natural result of a net neutral impact on total number of transplants.

The new policy creates six statuses to replace the three of the old policy: $1 \mathrm{~A}$ was changed to status 1,2 , and $3 ; 1 \mathrm{~B}$ to status 4 and 5 ; and 2 to status 6 . The new status 1 candidates are defined as individuals on VA ECMO or nondischargeable VADs, while status 2 includes intra-aortic balloon pumps and other percutaneous support devices. Status 3 includes patients on multiple inotropes or a single high-dose inotrope therapy and patients with a dischargeable LVAD with severe but not life-threatening complications. Status 4 includes those who do not fall within the parameters of the previous three statuses, including those on home inotrope therapy, those needing retransplants, those with stable dischargeable LVADs, and those with congenital, ischemic, and infiltrative cardiomyopathies as well as those with amyloidosis and hypertrophic cardiomyopathy.

The intended consequence of removing geographic considerations is that organs will be distributed to the sickest patients first (within 500 miles of the donor). The proportion of transplants within a local zone has decreased by $50 \%$. Whether this is a positive change or not is open to debate. It is unknown how the change will affect long-term posttransplant survival. Ischemic time will increase as teams fly around the country procuring the hearts. The patients being transplanted will be among the sickest on the waiting list; while they will be the most likely to derive benefit from the transplant, they will also be those most likely to experience an adverse outcome. In Texas, the overall number of transplants before and after the new policy has remained unchanged by initial early analysis, but it is still too soon to know how this change will impact any given program.

It is more important than ever for the transplant team to see NYHA functional class III and IV patients earlier rather 
than later in order to optimize the timing of their evaluation and their chance of obtaining an organ. Typically, these are individuals with chronic systolic heart failure who have been admitted twice within 6 months for acute decompensation and have an ejection fraction $<20 \%$ to $25 \%$. Meeting patients earlier will allow time for all the various elements to be evaluated, such as support system, comorbidities, and compliance-none of which can be adequately assessed once the patient is critical in an intensive care unit. Although it remains too early to reach a conclusion regarding the impact of the organ allocation change, waiting times may increase for individuals with end-stage heart failure who are not being supported in the hospital with ECMO or an LVAD.

\section{DISCUSSION}

There have been significant advances in the treatment of advanced heart failure over the past 5 years. However, much remains to be done. Future generations will likely look back in astonishment at the "primitive" technology currently in use, especially the need for external components and the dependence on short-lived battery power.

The explosive growth of knowledge currently taking place in medicine challenges physicians to "keep up" and to know when to reach out for specialty assistance and consultation. In advanced heart failure, referrals are often made late, with patients deprived of the benefits of advanced therapies. The 2013 ACC/AHA heart failure guidelines illustrate when providers should consider referring $\mathrm{HFrEF}$ patients to advanced heart failure clinicians. ${ }^{14}$ In a study highlighting

\section{Table 1. Guide for referral of patients to advanced heart failure services*}

\begin{tabular}{|c|c|}
\hline Criterion & Description \\
\hline 1 & Left ventricular ejection fraction $<40 \%$ \\
\hline 2 & $\begin{array}{l}\text { Dyspnea at rest or dyspnea, fatigue, or palpitations with } \\
\text { ordinary activities of life (New York Heart Association class III } \\
\text { to IV) } \\
\text { - Hospitalization for heart failure } \\
\text { - Implantable defibrillator shocks (if defibrillator present) } \\
\text { - Arrythmias (e.g., ventricular tachycardia, atrial fibrillation) } \\
\text { - Increasing diuretic dosing } \\
\text { - Furosemide } \geq 160 \mathrm{mg} / \mathrm{day} \\
\text { - Torsemide } \geq 80 \mathrm{mg} / \mathrm{day} \\
\text { - Bumetanide } \geq 4 \mathrm{mg} / \mathrm{day} \\
\text { - Worsening renal function } \\
\text { - Creatinine } \geq 1.6 \mathrm{mg} / \mathrm{dL} \\
\text { - Hyponatremia: Sodium }<135 \mathrm{mEq} / \mathrm{L} \\
\text { - Unexplained weight loss (cardiac cachexia) } \\
\text { - Desire for assistance and advice on long-term management }\end{array}$ \\
\hline
\end{tabular}

*There is no consensus on exact criteria, and cutoffs for the values cited vary from center to center. This is also true for age. Both 75 and 80 years of age may serve as a threshold for transplantation or advanced mechanical support. We did not include age to encourage individualized assessment and consideration of patients for whom such therapy might be of benefit. the importance of early referral, 68,772 HFrEF patients were studied from the National Heart Failure Audit for England and Wales. These patients were discharged from the hospital for heart failure exacerbation from 2007 to 2013 and either did not have follow-up scheduled, followed up with a primary care provider, or followed up with a cardiologist. The researchers found that 30-day mortality (odds ratio $0.7 ; 95 \%$ CI $0.55-0.89$ ) and 1-year mortality (odds ratio $0.81 ; 95 \%$ CI 0.68-0.95) were significantly lower for patients who were referred to a cardiologist after discharge compared to those who were not. ${ }^{52}$

A reduced ejection fraction $<40 \%$ should stimulate consideration for referral. Functional limitations with activity and a lack of terminal comorbidities often warrant referral to an advanced heart failure specialist (Table 1). Referral made too early is preferred to that made too late.

\section{ORCID}

Shelley A. Hall (D) http://orcid.org/0000-0002-5989-2934

1. Gustafsson F, Rogers JG. Left ventricular assist device therapy in advanced heart failure: patient selection and outcomes. Eur J Heart Fail. 2017;19(5):595-602. doi:10.1002/ejhf.779.

2. Xanthakis V, Enserro DM, Larson MG, et al. Prevalence, neurohormonal correlates, and prognosis of heart failure stages in the community. JACC Heart Fail. 2016;4(10):808-815. doi:10.1016/j.jchf.2016.05.001.

3. Lund LH, Edwards LB, Dipchand AI, et al. The registry of the International Society for Heart and Lung Transplantation: thirty-third adult heart transplantation report-2016; focus theme: primary diagnostic indications for transplant. J Heart Lung Transplant. 2016; 35(10):1158-1169. doi:10.1016/j.healun.2016.08.017.

4. Kirklin JK, Cantor R, Mohacsi P, et al. First annual IMACS report: a global International Society for Heart and Lung Transplantation registry for mechanical circulatory support. J Heart Lung Transplant. 2016; 35(4):407-412. doi:10.1016/j.healun.2016.01.002.

5. Thorvaldsen T, Lund LH. Focusing on referral rather than selection for advanced heart failure therapies. Card Fail Rev. 2019;5(1):24-26. doi:10.15420/cfr.2018.35.1.

6. Yancy CW, Januzzi JL Jr, Allen LA, et al. 2017 ACC expert consensus decision pathway for optimization of heart failure treatment: answers to 10 pivotal issues about heart failure with reduced ejection fraction: a report of the American College of Cardiology Task Force on Expert Consensus Decision Pathways. J Am Coll Cardiol. 2018;71(2): 201-230. doi:10.1016/j.jacc.2017.11.025.

7. CONSENSUS Trial Study Group. Effects of enalapril on mortality in severe congestive heart failure. Results of the Cooperative North Scandinavian Enalapril Survival Study (CONSENSUS). $N$ Engl J Med. 1987;316(23):1429-1435. doi:10.1056/NEJM198706043162301.

8. Yusuf S, Pitt B, Davis CE, Hood WB, Cohn JN, SOLVD Investigators. Effect of enalapril on survival in patients with reduced left ventricular ejection fractions and congestive heart failure. $N$ Engl J Med. 1991;325(5):293-302. doi:10.1056/NEJM199108013250501.

9. Cohn JN, Johnson G, Ziesche S, et al. A comparison of enalapril with hydralazine-isosorbide dinitrate in the treatment of chronic congestive heart failure. N Engl J Med. 1991;325(5):303-310. doi:10.1056/ NEJM199108013250502.

10. McMurray JJ, Packer M, Desai AS, et al. Angiotensin-neprilysin inhibition versus enalapril in heart failure. $N$ Engl J Med. 2014; 371(11):993-1004. doi:10.1056/NEJMoa1409077. 
11. Packer M, Califf RM, Konstam MA, et al. Comparison of omapatrilat and enalapril in patients with chronic heart failure: the Omapatrilat Versus Enalapril Randomized Trial of Utility in Reducing Events (OVERTURE). Circulation. 2002;106(8):920-926. doi:10.1161/01. CIR.0000029801.86489.50.

12. Sackner-Bernstein JD, Kowalski M, Fox M, Aaronson K. Short-term risk of death after treatment with nesiritide for decompensated heart failure: a pooled analysis of randomized controlled trials. JAMA. 2005; 293(15):1900-1905. doi:10.1001/jama.293.15.1900.

13. Yancy CW, Jessup M, Bozkurt B, et al. 2016 ACC/AHA/HFSA focused update on new pharmacological therapy for heart failure: an update of the 2013 ACCF/AHA guideline for the management of heart failure: a report of the American College of Cardiology/ American Heart Association Task Force on Clinical Practice Guidelines and the Heart Failure Society of America. J Am Coll Cardiol. 2016;68(13):1476-1488. doi:10.1016/j.jacc.2016.05.011.

14. Baran DA. Extracorporeal membrane oxygenation (ECMO) and the critical cardiac patient. Curr Transplant Rep. 2017;4(3):218-225. doi: 10.1007/s40472-017-0158-5.

15. Meuwese CL, Ramjankhan FZ, Braithwaite SA, et al. Extracorporeal life support in cardiogenic shock: indications and management in current practice. Neth Heart J. 2018;26(2):58-66. doi:10.1007/s12471018-1073-9.

16. Guglin M, Zucker MJ, Bazan VM, et al. Venoarterial ECMO for adults: JACC scientific expert panel. J Am Coll Cardiol. 2019;73(6): 698-716. doi:10.1016/j.jacc.2018.11.038.

17. Pineton de Chambrun M, Bréchot N, Combes A. Venoarterial extracorporeal membrane oxygenation in cardiogenic shock: indications, mode of operation, and current evidence. Curr Opin Crit Care. 2019; 25(4):397-402. doi:10.1097/MCC.0000000000000627.

18. King CS, Roy A, Ryan L, Singh R. Cardiac support: emphasis on venoarterial ECMO. Crit Care Clin. 2017;33(4):777-794. doi:10. 1016/j.ccc.2017.06.002.

19. Lescouflair T, Figura R, Tran A, Kilic A. Adult veno-arterial extracorporeal life support. J Thorac Dis. 2018;10(Suppl 15):S1811-S1818. doi:10.21037/jtd.2018.01.25.

20. Poptsov V, Spirina E, Dogonasheva A, Zolotova E. Five years' experience with a peripheral veno-arterial ECMO for mechanical bridge to heart transplantation. J Thorac Dis. 2019;11(S6):S889-S901. doi:10. 21037/jtd.2019.02.55.

21. Pappalardo F, Schulte C, Pieri M, et al. Concomitant implantation of Impella ${ }^{\circledR}$ on top of veno-arterial extracorporeal membrane oxygenation may improve survival of patients with cardiogenic shock. Eur J Heart Fail. 2017;19(3):404-412. doi:10.1002/ejhf.668.

22. Sun T, Guy A, Sidhu A, et al. Veno-arterial extracorporeal membrane oxygenation (VA-ECMO) for emergency cardiac support. J Crit Care. 2018;44:31-38. doi:10.1016/j.jcrc.2017.10.011.

23. Nersesian G, Hennig F, Müller M, et al. Temporary mechanical circulatory support for refractory heart failure: the German Heart Center Berlin experience. Ann Cardiothorac Surg. 2019;8(1):76-83. doi:10. 21037/acs.2018.12.01.

24. Cevasco M, Takayama H, Ando M, Garan AR, Naka Y, Takeda K. Left ventricular distension and venting strategies for patients on venoarterial extracorporeal membrane oxygenation. J Thorac Dis. 2019;11(4):1676-1683. doi:10.21037/jtd.2019.03.29.

25. Barge-Caballero G, Castel-Lavilla MA, Almenar-Bonet L, et al. Venoarterial extracorporeal membrane oxygenation with or without simultaneous intra-aortic balloon pump support as a direct bridge to heart transplantation: results from a nationwide Spanish registry. Interact Cardiovasc Thorac Surg. 2019;29(5):670-677. doi:10.1093/ icvts/ivz155.

26. Martits-Chalangari K, Hernandez O, Jamil AK, et al. Salvage of severe primary graft dysfunction following heart transplantation using extracorporeal life support. Proc (Bayl Univ Med Cent). 2018;31(4): 482-486. doi:10.1080/08998280.2018.1498724.
27. Guha A, Hannawi B, Cruz-Solbes AS, et al. Implication of ventricular assist devices in extracorporeal membranous oxygenation patients listed for heart transplantation. J Clin Med. 2019;8(5):572-584. doi: $10.3390 / \mathrm{jcm} 8050572$.

28. Urban M, Siddique A, Merritt-Genore H, Um J. What are the results of venoarterial extracorporeal membrane oxygenation bridging to heart transplantation? Interact Cardiovasc Thorac Surg. 2019;29(4):632-634. doi:10.1093/icvts/ivz096.

29. Tramm R, Ilic D, Davies AR, Pellegrino VA, Romero L, Hodgson C. Extracorporeal membrane oxygenation for critically ill adults. Cochrane Database Syst Rev. 2015;1:CD010381. doi:10.1002/ 14651858.CD010381.pub2.

30. Pozzi M, Banfi C, Grinberg D, et al. Veno-arterial extracorporeal membrane oxygenation for cardiogenic shock due to myocarditis in adult patients. J Thorac Dis. 2016;8(7):E495-E502. doi:10.21037/jtd. 2016.06.26.

31. Rao P, Khalpey Z, Smith R, Burkhoff D, Kociol RD. Venoarterial extracorporeal membrane oxygenation for cardiogenic shock and cardiac arrest. Cardinal considerations for initiation and management. Circ Heart Fail. 2018;11(9):1-17. doi:10.1161/CIRCHEARTFAILURE. 118.004905 .

32. Schiller P, Hellgren L, Vikholm P. Survival after refractory cardiogenic shock is comparable in patients with Impella and veno-arterial extracorporeal membrane oxygenation when adjusted for SAVE score. Eur Heart J Acute Cardiovasc Care. 2019;8(4):329-337. doi:10.1177/ 2048872618799745.

33. Mehmood M. Venoarterial extracorporeal membrane oxygenation in the new heart allocation scheme: time for concern or time to get our act together? Circ Heart Fail. 2018;11(9):1-2. doi:10.1161/ CIRCHEARTFAILURE.118.005322.

34. Le Gall A, Follin A, Cholley B, Mantz J, Aissaoui N, Pirracchio R. Veno-arterial-ECMO in the intensive care unit: from technical aspects to clinical practice. Anaesth Crit Care Pain Med. 2018;37(3):259-268. doi:10.1016/j.accpm.2017.08.007.

35. Liotta D, Taliani T, Giffoniello AH, et al. Artificial heart in the chest: preliminary report. Trans Am Soc Artif Intern Organs. 1961;7: 318-322.

36. Liotta D, Hall CW, Henly WS, Cooley DA, Crawford ES, Debakey ME. Prolonged assisted circulation during and after cardiac or aortic surgery. Prolonged partial left ventricular bypass by means of intracorporeal circulation. Am J Cardiol. 1963;12(3):399-405. doi:10.1016/ 0002-9149(63)90235-2.

37. Hall CW, Liotta D, Henly WS, Crawford ES, DeBakey ME. Development of artificial intrathoracic circulatory pumps. Am J Surg. 1964;108(5):685-692. doi:10.1016/0002-9610(64)90115-1.

38. US Department of Health and Human Services. Artificial Heart and Assist Devices: Directions, Needs, Costs, Societal and Ethical Issues. Bethesda, MD: National Institutes of Health; 1985: 25-27.

39. Institute of Medicine. The Artificial Heart: Prototypes, Policies, and Patients. Hogness JR, VanAntwerp M, eds. Washington, DC: National Academies Press; 1991.

40. Frazier OH, Duncan JM, Radovancevic B, et al. Successful bridge to heart transplantation with a new left ventricular assist device. $J$ Heart Lung Transplant. 1992;11(3 Pt 1):530-537.

41. Aaronson KD, Slaughter MS, Miller LW, et al; HeartWare Ventricular Assist Device (HVAD) Bridge to Transplant ADVANCE Trial Investigators. Use of an intrapericardial, continuous-flow, centrifugal pump in patients awaiting heart transplantation. Circulation. 2012;125(25):3191-3200. doi:10.1161/CIRCULATIONAHA.111. 058412 .

42. Rogers JG, Pagani FD, Tatooles AJ, et al. Intrapericardial left ventricular assist device for advanced heart failure. N Engl J Med. 2017; 376(5):451-460. doi:10.1056/NEJMoa1602954.

43. Milano CA, Rogers JG, Tatooles AJ, et al. HVAD: the ENDURANCE supplemental trial. JACC Heart Fail. 2018;6(9): 792-802. doi:10.1016/j.jchf.2018.05.012. 
44. Naftel DC, Kirklin JK, Myers SL. INTERMACS Statistical Report: March 1, 2006 - August 31, 2007. www.intermacs.org.

45. Mehra MR, Naka Y, Uriel N, et al; MOMENTUM 3 investigators. A fully magnetically levitated circulatory pump for advanced heart failure. $N$ Engl J Med. 2017;376(5):440-450. doi:10.1056/NEJMoa1610426.

46. Mehra MR, Uriel N, Naka Y, et al; MOMENTUM 3 investigators. A fully magnetically levitated left ventricular assist device-final report. $N$ Engl J Med. 2019;380(17):1618-1627. doi:10.1056/NEJMoa1900486.

47. Mehta SM, Pae WE Jr, Rosenberg G, et al. The LionHeart LVD2000: a completely implanted left ventricular assist device for chronic circulatory support. Ann Thorac Surg. 2001;71(3 Suppl):S156-S161. doi:10.1016/S0003-4975(00)02641-2.

48. Dowling RD, Gray LA, Jr, Etoch SW, et al. Initial experience with the AbioCor implantable replacement heart system. J Thorac Cardiovasc Surg. 2004;127(1):131-141. doi:10.1016/j.jtcvs.2003.07.023.
49. Pya Y, Maly J, Bekbossynova M, et al. First human use of a wireless coplanar energy transfer coupled with a continuous-flow left ventricular assist device. J Heart Lung Transplant. 2019;38(4):339-343. doi: 10.1016/j.healun.2019.01.1316.

50. Mehra MR, Salerno C, Cleveland JC, et al. Healthcare resource use and cost implications in the MOMENTUM 3 long-term outcome study. Circulation. 2018;138(18):1923-1934. doi:10. 1161/CIRCULATIONAHA.118.035722.

51. Organ Procurement and Transplantation Network. http://optn.transplant.hrsa.gov/. Accessed February 10, 2020.

52. Emdin CA, Hsiao AJ, Kiran A, et al. Referral for specialist follow-up and its association with post-discharge mortality among patients with systolic heart failure (from the National Heart Failure Audit for England and Wales). Am J Cardiol. 2017;119(3):440-444. doi:10. 1016/j.amjcard.2016.10.021.

\section{Avocations}

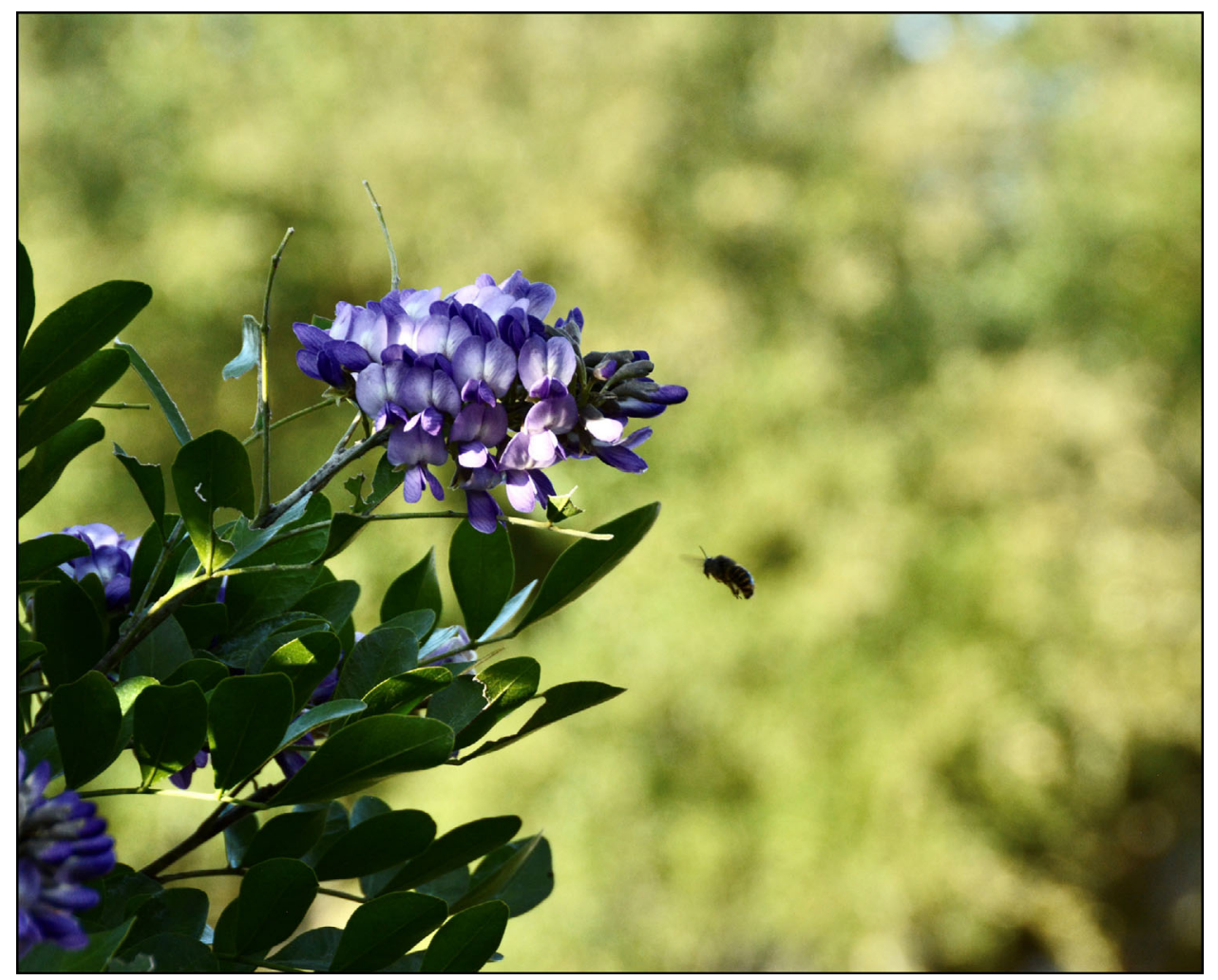

Photo by Alejandro C. Arroliga, MD. Dr. Arroliga (Alejandro.Arroliga@BSWHealth.org) is executive vice president and chief medical officer of Baylor Scott \& White Health. 